\title{
SELF-EFFICACY AMONG INDONESIAN CHRONIC LIVER DISEASE PATIENTS
}

\author{
Apriliani Siburian $^{1 *}$, Ching-Fen Chang ${ }^{2}$ \\ ${ }^{1}$ Program Studi S1 Keperawatan, STIKes Tarumanagara, Jakarta, Indonesia \\ ${ }^{2}$ School of Nursing, National Taipei University of Nursing and Sciences, Taiwan \\ *Correspondence email: s.aprilia@stikes.tarumanagara.ac.id
}

\begin{abstract}
Chronic Liver Diseases are among the most extensive diseases globally and are related to significant morbidity and mortality. Although physical well-being has long been the primary goal of medical care, as chronic disease becomes more prevalent in developed countries, there has been a greater focus on patients' emotional and social well-being. This study aimed to describe the self-efficacy among chronic liver disease patients in North Sumatra, Indonesia. This study uses a cross-sectional design. The study assessed 102 chronic liver disease patients from two hospitals using the Chronic Disease Self-Efficacy Scales Indonesian version. The participants had moderate self-efficacy (58.8\%), followed by high selfefficacy (38.2\%). The majority of the patients in this study had moderate self-efficacy because many individuals with chronic liver disease suffer chronic fatigue, abdominal pain and swelling, itchy skin, nausea or vomiting, loss of appetite, and other symptoms that affect self-efficacy. Health professionals should strengthen patients' self-efficacy by engaging in positive activities and enhancing their coping skills.
\end{abstract}

Keywords: Chronic Liver Disease, Self-efficacy

\section{INTRODUCTION}

Chronic Liver Disease (CLD) has shown a serious impact on patients' well-being and devotes to the important morbidity associated with these conditions. ${ }^{1}$ Chronic Liver Diseases are among the most extensive diseases globally and are related to significant morbidity and mortality. Hepatitis B virus (HBV) and hepatitis $\mathrm{C}$ virus (HCV) are the major familiar causes of CLD, with $\mathrm{HBV}$ estimated to affect 360 million people worldwide and HCV affecting another 200 million. Several distinct complications of cirrhosis include hepatic encephalopathy, ascites, and variceal bleedings. ${ }^{2}$ And also, jaundice, fatigue, dyspnea and can affect daily life. These complications seriously affect the quality of life for patients with CLD, as these patients suffer many effects.

Self-efficacy attributes an individuals' perception about whether they can achieve a particular activity. In another way, it is an individual's judgment or level of confidence about what they can and cannot do pass the various tasks and situations. Self-efficacy creates a disparity in how people feel, think, and act. ${ }^{3}$ Self-efficacy relates to a general sense of confidence in people's abilities to accomplish the desired outcome. Selfenhancing or self-debilitating ways in how individuals think optimistically or pessimistically, affected by efficacy belief. ${ }^{4}$ Researchers found an association between self-efficacy and mild physical activity ${ }^{5}$. Patients who can manage their chronic diseases are urged to partner with professionals to learn the most effective ways to maintain a high quality of life at home.

Self-efficacy refers to confidence inability to achieve specific achievement. In general, chronic liver diseases are deliberate in progression, long in duration, and require medical treatment because the long recrudescent course of the disease exercises a considerable negative effect on patient health and lifestyle. ${ }^{6}$ 
Indonesia is the third country of hepatitis $B$ in the Asia Pacific region after China and India. Approximately 13 million Indonesians have been affected by hepatitis $B$, and about four (4) million are affected by hepatitis C. Quality of life may be diminished in patients with chronic liver diseases. HRQoL defines patients' subjective assessment regarding the physical, mental, and social dimensions of well-being. And it has also altered to an important part in clinical and epidemiological studies in gastroenterology and hepatology. ${ }^{7}$

Understanding chronic liver disease patients' self-efficacy can help increase patients' quality of life with this disease. This research is also expected to provide additional information for nurses and health workers to pay more attention to patients with chronic liver disease self-efficacy.

\section{MATERIAL AND METHODS}

This is a cross-sectional study using the Chronic Disease Self-Efficacy Scales Indonesian Version instruments that consist of 33 questions. Stanford Patient Education Research Center develops the scale to define self-efficacy for all kinds of chronic diseases. The questionnaire has done forward and backward translation. ${ }^{8}$ Scoring of the questionnaires divided into three categories, namely low (33-132), medium (133-231), and high (232-330) self-efficacy. It used a quantitative approach to describe the demography and self-efficacy of the patients in two hospitals. Descriptive statistics were calculated for the study population. This study was conducted on Sumatra island, namely North Sumatra, Indonesia. The self-efficacy instrument using

This study used purposive sampling, recruited all the chronic liver disease patients based on the inclusion and exclusion criteria from two hospitals as respondents in that period. There are 102 participants (63 patients from Adam Malik General Hospital and 39 patients from Sidikalang General Hospital). The patients who visited the outpatients and inpatients department were invited to participate in the study. The researcher waited for the patients at the outpatient department clinic and visited the patients who stay in the inpatient department.

This study's inclusion criteria were inpatients or outpatients with chronic liver disease over a period greater than six months, ${ }^{9}$ and patients must be able to answer the questionnaire questions (compos mentis). Patients must be able to read in Indonesian. They must prove their ability when researchers ask respondents to fill out the questionnaire's demographic data, and patients must be above 18 years old (adults). Patients must be willing to participate in the study and sign an informed consent form. The exclusion criteria were patients with acute liver disease (disease of the liver that lasts longer than six months), patients with chemotherapy (liver cancer), the latest chronic liver diseases, and liver transplantation. Patients admitted to the hospital for the first time (not chronic) and unconscious patients.

\section{RESULT}

The demographic of participants is shown in Table 1. The average age was 46.04 years old; the youngest participant was 18 years old, and the oldest was 88 years old. A majority of participants were in the 41-60year-old age group $(n=48,47.1 \%)$. Males were $52.9 \%$ of the total population $(n=54)$. $82.4 \%(n=84)$ of participants were classified as having a low education level regarding education level. Most of the participants were self-employed, at $86.3 \%(n=88)$. Participants who were married constituted $83.3 \% \quad(n=85)$ of the total. The chronic liver disease duration since diagnosis for half of the participants $(50 \%, n=51)$ was less than one year (more than six months). Regarding religion, most of the participants were Christian, accounting for $62.7 \%(n=64)$. Significantly, the most ethnicities among the participants were Batak, at $72.5 \%$. Overall, a slight majority of participants $(54,9 \%)$ had monthly incomes less than 1,500 IDR.

The results on the Self-Efficacy scale are shown in Table 4.2. Self-Efficacy was tested 
using Chronic Disease Self-Efficacy Scales Indonesian Version. It found that most respondents had middle Self-Efficacy that contributes $58.9 \%$, followed by high SelfEfficacy (38.2\%) and low Self-Efficacy with $2.9 \%$.

Table 1. Descriptive Characteristics of Participant

\begin{tabular}{|c|c|c|}
\hline Variable & $N$ & $\%$ \\
\hline \multicolumn{3}{|l|}{ Age } \\
\hline $20-40$ & 39 & 38.2 \\
\hline $41-60$ & 48 & 47.1 \\
\hline$>61$ & 15 & 14.7 \\
\hline \multicolumn{3}{|l|}{ Gender } \\
\hline Male & 54 & 52.9 \\
\hline Female & 48 & 47.1 \\
\hline \multicolumn{3}{|l|}{ Occupation } \\
\hline Self-employed & 88 & 86.3 \\
\hline Civil servant & 14 & 13.7 \\
\hline \multicolumn{3}{|l|}{ Marital status } \\
\hline Married & 85 & 83.3 \\
\hline Single & 17 & 16.7 \\
\hline \multicolumn{3}{|c|}{ Duration Since Diagnosis } \\
\hline$<1$ year & 51 & 50 \\
\hline$>1$ year- 2 years & 33 & 32.4 \\
\hline$>2$ years & 18 & 17.6 \\
\hline \multicolumn{3}{|l|}{ Religion } \\
\hline Muslim & 33 & 32.4 \\
\hline Christian & 64 & 62.7 \\
\hline Other & 5 & 4.9 \\
\hline \multicolumn{3}{|l|}{ Ethnicity } \\
\hline Javanese & 23 & 22.5 \\
\hline Batak & 74 & 72.5 \\
\hline Other & 5 & 5 \\
\hline \multicolumn{3}{|l|}{ Monthly income } \\
\hline$<$ IDR 1,500 & 56 & 54.9 \\
\hline IDR $1,600-3,000$ & 30 & 29.4 \\
\hline$>$ IDR 3,000 & 16 & 15.7 \\
\hline
\end{tabular}

Table 2. Descriptive Statistics of Self

\begin{tabular}{lcc}
\multicolumn{3}{c}{ Efficacy } \\
\hline Variable & $N$ & $\%$ \\
\hline Self-Efficacy & & \\
Low SE & 3 & 2.9 \\
Middle SE & 60 & 58.9 \\
High SE & 39 & 38.2 \\
\hline
\end{tabular}

\section{DISCUSSION}

The total number of participants was 102 outpatients and inpatients. The average age was 46.04 years old, with the youngest participant 18 years old and the oldest 88 years old. At $47.1 \%$, the highest number of participants was in the $41-60$ age group. The 20 - 40 age group accounted for $38.2 \%$ of participants, with $14.7 \%$ of participants over 60 years old. The participants' average age in this study was similar to a study of 72 cirrhosis patients conducted in Iran, ${ }^{10}$ who also had an average age of 47 years old. The study set out to evaluate the effectiveness of an educational intervention for patients with liver cirrhosis. That study used the Chronic Liver Disease Questionnaire and a knowledge questionnaire to assess patients' knowledge and quality of life. The findings of participants' age from this study and another study because of patients over 40 years old were likely suffered from chronic liver disease than other age groups.

A study was assessed to determine whether HRQL (health-related quality of life) in patients with chronic liver disease differs by type and severity of the liver disease. They also aimed to identify which clinical and physiological factors affect liver function. Like this study, chronic liver disease patients had an average age of 50, with $51 \%$ men $^{11}$.

Participants in a study conducted in South Korea ${ }^{12}$ also had similar demographic characteristics to those of this study. The total number of chronic liver disease patients was 139 drawn from the sixth Korean National Health and Nutrition Examination Survey (KNHNES VI). In that study, most patients $(56.9 \%)$ were in the 45-64 age group, only slightly older than the most populous age group of 41-60 in this study; the average age of participants was also slightly older at 55.3 years. Kim et al. likewise mentioned that most of the respondents were male $(62.6 \%)$. It might be caused by alcohol-consuming by most of the males. Batak's male was popular with drinking "tuak", the traditional alcohol since they were young. A study by the research team at the University of California 
in 2007 stated that the production of a protein that promotes inflammation appears to be linked to higher liver cancer in men than in women. Regarding the level of education, at $82.4 \%$, the number of participants with low education in this study was somewhat higher than $72.2 \%$ in the Korean study. In the Korean study, participants who were married and living with their spouses accounted for $81.2 \%$ of total participants. At $83.3 \%$, the number of married respondents was slightly higher in this study.

In this study, the duration of the chronic liver disease since diagnosis for half of the participants was less than one year (more than six months), followed by one year to 2 years at $32.4 \%$, with $17.6 \%$ of patients diagnosed than two years ago. The patients in this study were quite different from those in a study of hepatitis B surface antigen-positive patients, ${ }^{11}$ in which the majority of patients $(60 \%)$ had been diagnosed more than ten years ago. That study also used a cross-sectional design. The data in that study were collected from the patients using different tools, namely, the LDSI 2.0, Chronic Liver Disease Questionnaire, and EuroQol.Their sample's mean age was 43.3 years, and the majority of patients were men $(77.6 \%)$. Nearly $90 \%$ of the patients in this Iranian sample were married, compared to $83.3 \%$ in this study, and more than half of them were employed (56.1\%), whereas all the patients in this study were employed. Most of the Iranian patients lived in urban areas $(97.1 \%)$.

A study of chronic viral liver disease patients conducted in Serbia. They found that the mean age for patients with chronic viral liver disease was 39 years old, with participants ranging from age 16 to 66 years, and a high percentage of males $(64.3 \%)$. Most of the participants in the Serbian study were also married, constituting $61.7 \%$ of the total. ${ }^{7}$

Self-efficacy is an individual's belief in their innate ability to achieve goals. Albert Bandura defines it as a personal judgment of "how well one can execute courses of action required to deal with prospective situations." People always struggle to control situations that influence their lives. ${ }^{3}$ Perceived selfefficacy is defined as a person's beliefs about their capabilities to perform tasks at the desired level. Self-efficacy beliefs determine how people feel, think, motivate themselves, and behave.

This study measured self-efficacy among chronic liver disease patients using the Chronic Disease Self-efficacy Scales created by Psychometric Data Stanford for its Chronic Disease Self-Management Study. This psychometric instrument was made available and free for public use by Lorig and colleagues' in $1996 .{ }^{13}$ Since this study was conducted in Indonesia, the researcher used the Indonesian version. To measure selfefficacy, this study used the Chronic Disease Self-efficacy Scales, which consists of 39 questions. The Indonesian version was validated in a study of chronic kidney disease patients in Indonesia recruited 39 respondents. ${ }^{14}$ The questionnaire consists of ten indicators, namely, regular exercise (three items), getting information on the disease (one item), obtaining help from the community, family, friends (four items), communicating with physicians (three items), managing the disease in general (five items), doing chores (three items), doing social/recreational activities (two items), managing symptoms (five items), managing shortness of breath (one item), and controlling/managing depression (six items).

This study's findings showed that a substantial majority of participants had moderate self-efficacy $(\mathrm{n}=60,58.8 \%)$. In comparison, about $40 \%$ had high self-efficacy $(\mathrm{n}=39,38.2 \%)$, and a tiny minority had low self-efficacy $(n=3,2.9 \%)$. Self-efficacy may increase or decrease over time, depending on life events. The questionnaire could be used by nurses, social workers, and other health professionals to strengthen patients' selfefficacy by engaging in activities it describes, such as encouraging or accompanying patients to ask doctors questions and informing doctors of it in advance. It is possible that most of the patients in this study had moderate self-efficacy because many 
individuals with the chronic liver disease suffer chronic fatigue, abdominal pain and swelling, itchy skin, nausea or vomiting, loss of appetite, and other symptoms that affect self-efficacy.

The findings of this study were similar to those of another chronic disease study among patients with COPD. They found that most of the participants had low self-efficacy. The study explained that symptoms - specifically, breathing difficulties while participating in many activities-were a major reason ${ }^{15}$. A study conducted in Israel rated the selfefficacy among nonalcoholic fatty liver disease patients as medium-high. The same study pointed out that self-efficacy was lower among nonalcoholic fatty liver disease patients than patients with other liver diseases. Sagi et al. explained the role of selfefficacy as a determinant of patients' success at maintaining lifestyle modifications. In general, most chronic disease patients have moderate to low self-efficacy. However, a study of chronic kidney disease patients conducted in Indonesia produced different results, finding high self-efficacy among almost two-thirds (66.67\%) of those patients. ${ }^{13}$ However, previous studies about self-efficacy among patients with chronic liver disease are scarce, pointing to a need for more studies that test the self-efficacy, especially in chronic liver disease

\section{CONCLUSION}

Healthcare professionals should design supportive programs for older patients to strengthen their self-efficacy and educate them about the disease and where to go for treatment since chronic liver disease requires cooperation from both patients and healthcare providers. In addition, nurses should collaborate with other departments to arrange a private counseling room so that patients who need to talk privately with health providers can do so. A private space is needed to discuss life events that affect self-efficacy since other hospitals do not afford this. Nurses should also encourage patients to form support groups outside the hospital. Also, nurses or healthcare professionals should encourage the family to take care of the patients.

\section{REFERENCES}

1. Martin LM., Sheridan MJ, Younossi ZM. The impact of liver disease on healthrelated quality of life: a review of the literature. Current gastroenterol rep.;2002. 4:79-83

2. Gutteling J, De Man R, Busschbach J, \& Darlington A. Overview of research on health-related quality of life in patients with chronic liver disease. Neth J Med. 65(7). 2007. page 227-234.

3. Bandura A. Self-efficacy: The exercise of control. New York: W. H. Freeman, 1997.

4. Urdan T ,Pajares F. Self-Efficacy Beliefs of Adolescents. University of Colorado School of Education.Copyright 2006 by Information Age Publishing. 2006.

5. Kaplan RM, Atkins CJ, \& Reinsch S. Specific efficacy expectations mediate exercise compliance in patients with COPD. Health Psychology, 3 (5). 1984. page 223-242.

6. Tehranian S, Jafari S, Yousofi J, Kiani M., Seyedin S., Khakshour A, Kianifar H. Health-related quality of life (HRQOL) in children with chronic liver disease in North East Iran using PedsQL ${ }^{\mathrm{TM}}$ 4.0. Electronic

Physician, 7(4). 2015. page 1214-1219. http://doi.org/10.14661/2015.1214-1219

7. Svirtlih N, Pavic S, Terzic D, Delic D, Simonovic J, Gvozdenovic E, \& Boricic I. Reduced quality of life in patients with chronic viral liver disease as assessed by SF12 questionnaire. J Gastrointestin Liver Dis, 17(4). 2008; 405-409.

8. Rizkya I. Hubungan antara Self-efficacy dengan Kualitas Hidup pada Pasien Gagal Ginjal Kronis yang menjalani Hemodialisa di Rumah Sakit "X" Kota Bandung. University of padjajaran journal. Thesis.2016.

9. Sharma A, Nagalli S. Chronic Liver Disease. In: StatPearls [Internet]. Treasure Island (FL): StatPearls 
Publishing; 2020 Jan-. Available from: https://www.ncbi.nlm.nih.gov/books/NB K554597/

10. Alavinejad P, Hajiani E, Danyaee B, Morvaridi M. The effect of nutritional education and continuous monitoring on clinical symptoms, knowledge, and quality of life in patients with cirrhosis. Gastroenterology and hepatology bed bench. 12(1).2019; 17-24.

11. Younossi M, Boparai Z, Price N, Kiwi L, McCormick M , Guyatt M., \& Gordon. Health-Related Quality of Life in chronic liver disease: the impact of type and severity of disease. The American Journal of Gastroenterology .96(7). 2001; 2199-205.

12. Kim HJ, Chu H, \& Lee S. Factor influencing on health-related quality of life in South Korean with chronic liver disease. Health and quality of life outcomes. 16(142).2018.doi:12955-0180964-1

13. Safari M, Alvian S, Naderi M., Pakpour A, Zaben F., \& Koenig H. Cross-Cultural Adaptation and Psychometric Assessment of the Liver Disease Symptom Index 2.0 to Measure HealthRelated Quality of Life Among Iranian Patients With Chronic Hepatitis B. Journal of Transcultural Nursing. 2016; 27(5). 496-508.

14. Lorig K, Stewart A, Ritter P, Gonzalez V, Laurent D, \& Lynch J. Outcome Measures for Health Education and other Health Care Interventions. Thousand Oaks CA: Sage Publications.1996; pp.2425,41-45.

15. Wigal JK, CreerTL., \& Kotses H. The COPD Self-efficacy Scale. US National Library of Medicine National Institutes of Health. 1991;99(5):1193-6. 